\title{
Embedment Strength of Tropical Timber Species
}

\author{
Hettiarachchi M.T.P. and Nawagamuwa A.D.
}

Dept. of Civil Engineering, University of Moratuwa

Abstract-The objective of this study was to determine the embedment strength of tropical timber species. The study was limited to five timber species representing densities from $300 \mathrm{~kg} / \mathrm{m}^{3}$ to 900 $\mathrm{kg} / \mathrm{m}^{3}$. The embedment strengths were determined in directions parallel to and perpendicular to the grain of timber and were determined on timber thicknesses of $25 \mathrm{~mm}, 38 \mathrm{~mm}$ and $50 \mathrm{~mm}$ using bolts of diameter $9.5 \mathrm{~mm}, 12.5 \mathrm{~mm}$ and $15.9 \mathrm{~mm}$. The experimental results obtained were compared with the recommendations of the Eurocode. It was found that these recommendations need to be modified for tropical timber species and this paper provides the modified equations.

\section{Background}

The embedment strength of timber is essential to calculate the design resistance capacity of timber bolted joints when using the European Yield Model (EYM). The EYM is now the basis for the determination of strength of timber joints in most codes of practice [1]. The application of the EYM to bolted joints of timber species indigenous to Sri Lanka has been discussed previously [2].

The embedment strength is defined in EN 383: (1993) [3], as the average compressive stress at maximum load in a piece of timber or timber-based sheet material product under the action of a stiff linear fastener while the fastener's axis is perpendicular to the surface of specimen and the fastener is loaded perpendicular to its axis.

The embedment strength can be determined, experimentally, in accordance with EN 383: (1993) [3]. This test can be regarded as a symmetrical three-piece joint test, using steel side members and a timber or timber-based sheet material central member in which a bearing failure is enforced under lateral load (Fig: 1).

Manuscript received: 03.03 .2003

Revised manuscript received: 30.08 .2004

Manuscript accepted: 05.01.2005

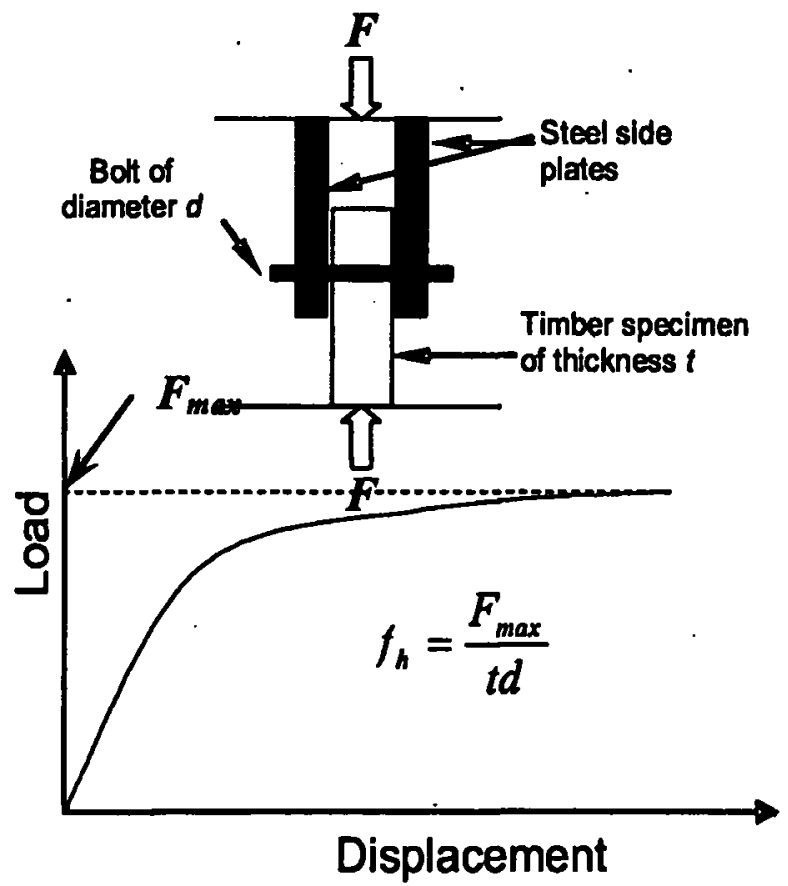

Fig: I Schematic diagram illustrating the embedment strength test apparatus and determination of embedment strength using load-displacement curve

Annex A of EC5 [4] provides the following formulae to calculate the characteristic embedment strength, $f_{h, k}$, for bolts up to $30 \mathrm{~mm}$ diameter:

timber loaded parallel to the grain,

$f_{h, 0, k}=0.082(1-0.01 d) \rho_{k} \mathrm{~N} / \mathrm{mm}^{2}$

timber loaded at an angle to the grain,

$f_{h a, k}=\frac{0.082(1-0.01 d) \rho_{k}}{k_{90} \operatorname{Sin}^{2} \alpha+\operatorname{Cos}^{2} \alpha} \mathrm{N} / \mathrm{mm}^{2}$ 
in which

$\rho_{k}=$ characteristic density of timber in $\mathrm{kg} / \mathrm{m}^{3}$

$\mathrm{d}=$ diameter of fastener in $\mathrm{mm}$

$\alpha=$ direction of load with respect to the grain direction of timber (degrees)

for,

hardwoods: $\mathrm{k}_{90}=0.90+0.0015 d$

The embedment strength depends on the type of fastener (whether nails, or bolts) the direction of loading (for bolts only), the density of timber and the diameter of the fastener. Thus, the embedment strength is not a special material property, but a joint property.

The EC 5 equations for the determination of embedment strength of timber are based on research conducted in Europe using five softwood timber species, and two hardwood timber species [5]. The softwood timber joints were made with bolts of M8, M12, M16 and M20 sizes while the two hardwood timber (Keruing and Greenheart) joints consisted only of M12 and M20 bolts The test series which was conducted to develop embedment strength formulae is discussed in several papers $[6,7,8$ and 9].

\section{Test Programme}

This paper discusses a test series that was conducted to check the validity of the EC5 equations to predict embedment strength for some indigenous hardwoods of Sri Lanka. The species selected for the test series are Lunumidella, Ginisapu, Hora, Kumbuk, and Palu. The oven dry densities of these timbers range from $300 \mathrm{~kg} / \mathrm{m}^{3}$ to $900 \mathrm{~kg} / \mathrm{m}^{3}$. Bolted joints made from these timber species were tested in both parallel and perpendicular to grain directions. The joints were made with bolts of diameters, $9.5 \mathrm{~mm}, 12.7 \mathrm{~mm}$ and 15.9 $\mathrm{mm}$. The timber specimens tested were of 25 $\mathrm{mm}, 38 \mathrm{~mm}$ and $50 \mathrm{~mm}$ thicknesses. However, for the $9.5 \mathrm{~mm}$ diameter bolts, the specimens were of $25 \mathrm{~mm}$ and $38 \mathrm{~mm}$ thickness in order to comply with the requirement of maintaining the specimen thickness within the range between 1.5 and 4 times the bolt diameter. Three replicates from each specimen were tested and thus a total of 240 tests were carried out (Table 1). Specimen size in relation to bolt size is shown in Fig: 2.

Table 1- Test Programme

\begin{tabular}{|l|c|c|}
\hline \multicolumn{1}{|c|}{$\begin{array}{c}\text { Species Tested } \\
(\text { density kg/m })\end{array}$} & $\begin{array}{c}\text { Bolt dia. } \\
(\mathbf{m m})\end{array}$ & $\begin{array}{c}\text { Member } \\
\text { thickness } \\
(\mathbf{m m})\end{array}$ \\
\hline Lunumidella $\left(333 \mathrm{~kg} / \mathrm{m}^{3}\right)$ & 9.5 & 25 \\
Ginisapu $\left(500 \mathrm{~kg} / \mathrm{m}^{3}\right)$ & & 38 \\
\cline { 2 - 3 } Hora $\left(637 \mathrm{~kg} / \mathrm{m}^{3}\right)$ & 12.7 & 25 \\
Kumbuk $\left(789 \mathrm{~kg} / \mathrm{m}^{3}\right)$ & & 38 \\
& & 50 \\
\cline { 2 - 3 } Palu $\left(911 \mathrm{~kg} / \mathrm{m}^{3}\right)$ & 15.9 & 25 \\
& & 38 \\
& & 50 \\
\hline
\end{tabular}

The apparatus used in the test series is illustrated in Fig: 3. It consisted of adjustable steel side plates, which have a circular hole at the bottom portion of the plate. The hole diameters for fasteners were $2 \mathrm{~mm}$ larger than the bolt size and were so selected such that there is no rotation nor vertical movement of bolt within the hole. No tightening was applied to the bolts. Side plates were attached to the horizontal beam for convenience so that the distance between plates could be adjusted according to the thickness of the test specimen. No friction was applied on the timber specimen as the side plates did not touch it.

Details of the test apparatus are given in [10]. 


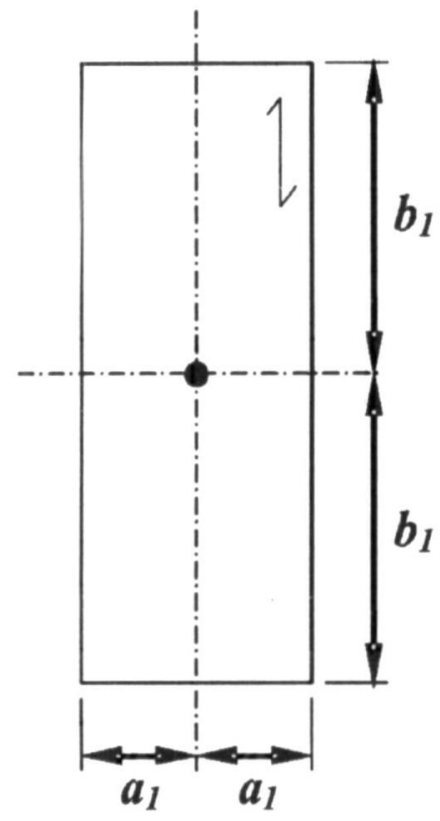

\section{i. Parallel to grain loading}

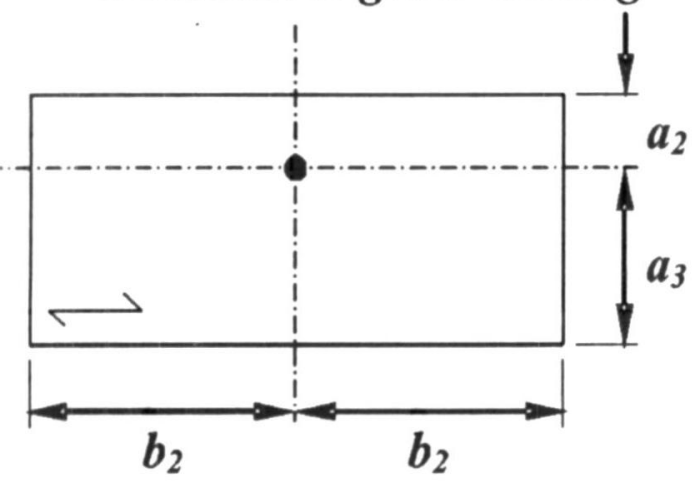

ii. Perpendicular to grain loading

$$
\begin{array}{lll}
a_{1}=3 d & a_{2}=2 d & b_{2}=7 d \\
b_{1}=7 d & a_{3}=4 d &
\end{array}
$$

$d$ is bolt diameter

\section{$\longrightarrow$ : grain direction}

Fig: 2 End and edge distances of embedment strength test specimen [3]

Specimens were tested in compression and load-slip data were continuously recorded for each joint. The ultimate load, that is resisted by the specimen was determined using the loadslip curve and the embedment strength was then calculated as specified in [3] (refer to Figure 1).

The density of each member was determined using the actual dimensions and the weight of the specimen measured just before the start of the test. The moisture content was determined

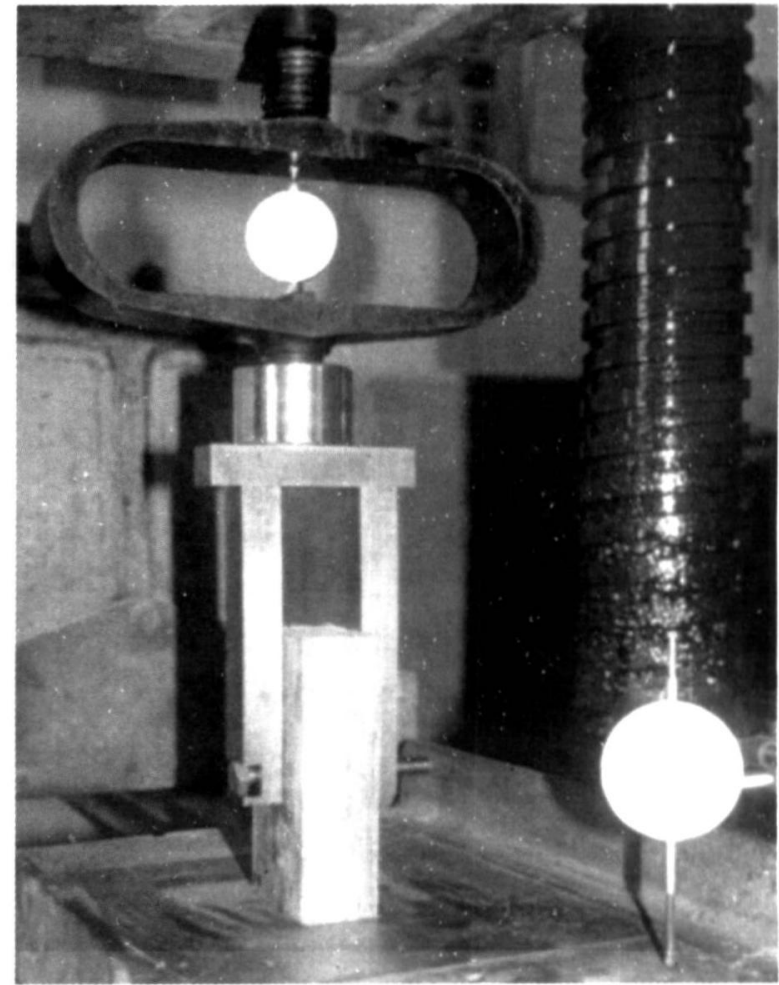

Fig: 3 Testing of specimen for embedment strength in parallel to grain loading direction

by adopting the oven-dried method using a piece of member cut from the specimen just after the test.

\section{Embedment strength test results}

The variations of embedment strength in both directions, parallel to grain and perpendicular to grain, with density of the timber at the time of test, are plotted in Figures 4.1 to 4.6 for specimens comprising different bolt diameters. The experimental embedment strength of each specimen is determined according to EN 383:1993 [3]. A comparison is also made with the theoretical embedment strength which is determined using Equations 1 and 2 for parallel and perpendicular to grain directions respectively.

A regression analysis of the experimental results with the density of the species at the time of test was carried out. These regression analyses were done for each loading direction and each bolt diameter. Several types of 
regression were applied and, among them, the linear regression was selected as the most suitable as it resulted in a more realistic and simple relationship.

As a whole, the experimental embedment strength and the embedment strength predicted by EC 5 [4] compare well with each other. When considering the parallel to grain loading test results (Figures 4.1 to 4.3 ), it can be seen that the agreement is best for smaller $(9.5 \mathrm{~mm})$ bolt diameters while with the increasing of bolt diameter up to $15.9 \mathrm{~mm}$, deviation between embedment strengths predicted by EC 5 [4] and experimental results increases. It can be seen that the opposite is true for perpendicular to grain loading. The best agreement is seen for the specimens tested with $15.9 \mathrm{~mm}$ bolts and the deviation of experimental results from the EC 5 [4] prediction increases when the bolt diameter decreases to $9.5 \mathrm{~mm}$ (Figures 4.4 to 4.6).

It is also evident that the deviation between the predicted and the experimental results increases with increase in density.

There appeared to be no significant dependence of the embedment strength on moisture content in the moisture content range tested (from $10 \%$ to $20 \%$ ).

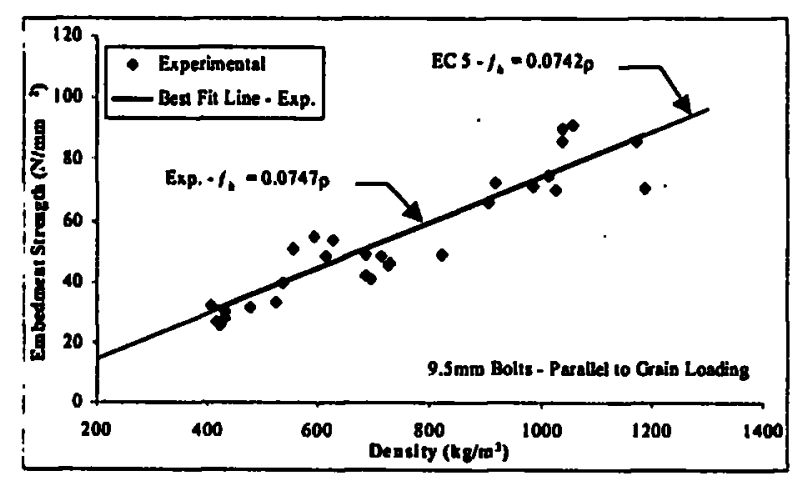

Fig: 4.1 Variation of embedment strength with density Comparison of experimental results with ECS values $9.5 \mathrm{~mm}$ bolts loaded parallel to the grain direction

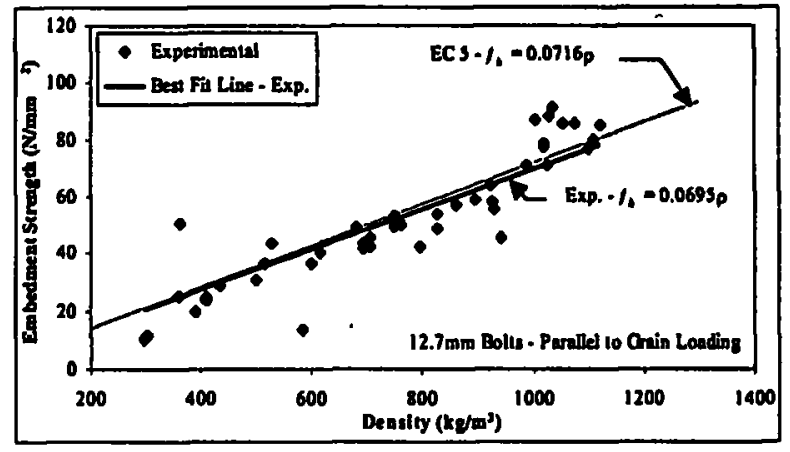

Fig: 4.2 Variation of embedment strength with density Comparison of experimental results with ECS values $12.7 \mathrm{~mm}$ bolts loaded parallel to the grain direction

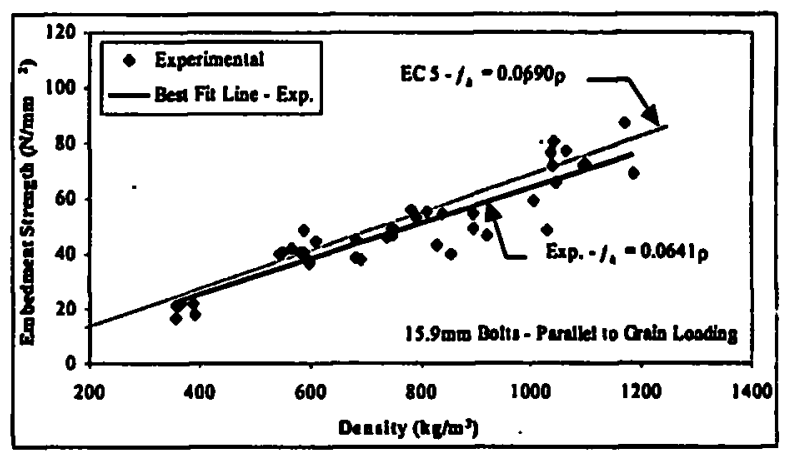

Fig: 4.3 Variation of embedment strength with density Comparison of experimental results with EC5 values $15.9 \mathrm{~mm}$ bolts loaded parallel to the grain direction

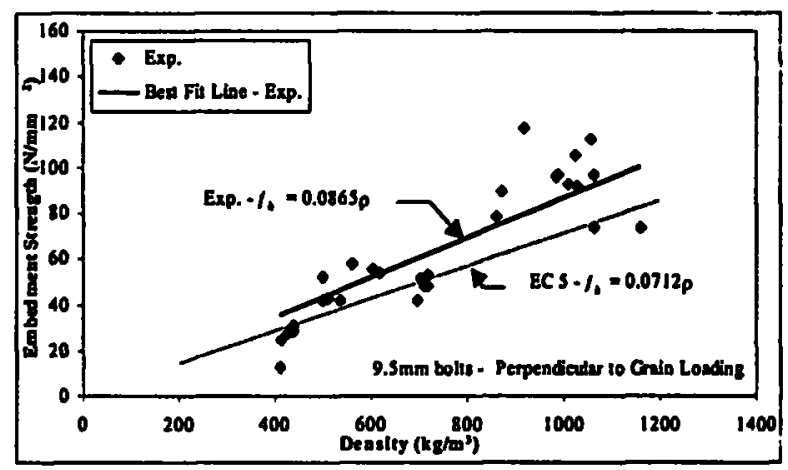

Fig: 4.4 Variation of embedment strength with density Comparison of experimental results with EC5 values $9.5 \mathrm{~mm}$ bolts loaded perpendicular to the grain direction 


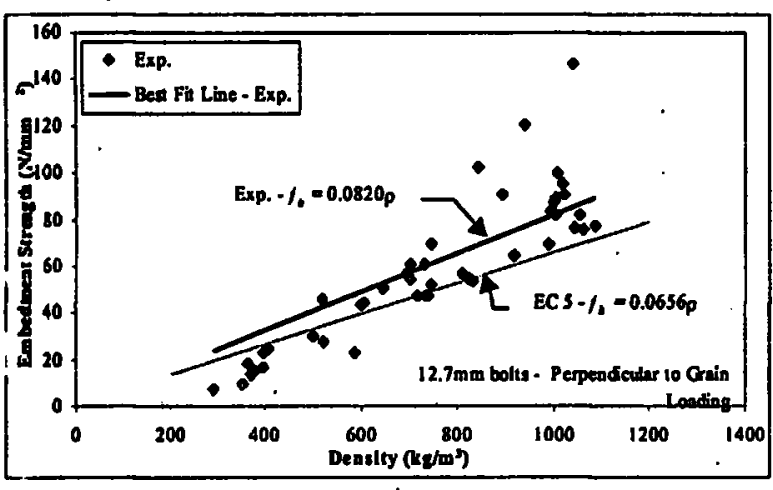

Fig: 4.5 Variation of embedment strength with density Comparison of experimental results with EC5 values $12.7 \mathrm{~mm}$ bolts loaded perpendicular to the grain direction

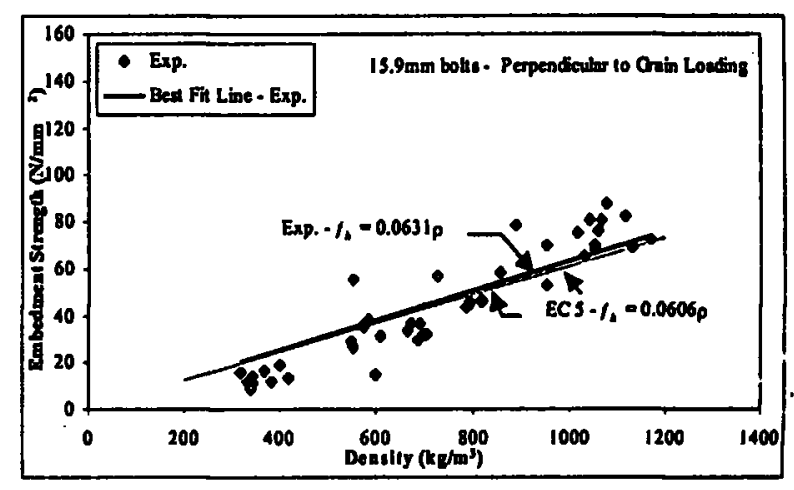

Fig: 4.6 Variation of embedment strength with density Comparison of experimental results with EC5 values $15.9 \mathrm{~mm}$ bolts loaded perpendicular to the grain direction

Table 2 - Results of linear regression analysis of maximum embedment strength against timber density

\begin{tabular}{|l|c|c|c|c|c|}
\hline \multicolumn{1}{|c|}{$\begin{array}{c}\text { Loading } \\
\text { direction }\end{array}$} & $\begin{array}{c}\text { Bolt diameter } \\
(\mathbf{m m})\end{array}$ & $\begin{array}{c}\text { No. of } \\
\text { specimens } \\
\text { tested }\end{array}$ & $\mathbf{R}^{2}$ (Exp.) & $\begin{array}{c}\text { Regression } \\
\text { against density } \\
\text { (Exp.) }\end{array}$ & $\begin{array}{c}\text { Regression. } \\
\text { against } \\
\text { density (EC 5) }\end{array}$ \\
\hline \multirow{2}{*}{$\begin{array}{l}\text { Parallel to } \\
\text { grain }\end{array}$} & 9.5 & 30 & 0.8164 & $0.0747 \rho$ & $0.0742 \rho$ \\
\cline { 2 - 6 } & 12.7 & 45 & 0.8192 & $0.0695 \rho$ & $0.0716 \rho$ \\
\cline { 2 - 6 } & 15.9 & 45 & 0.8472 & $0.0641 \rho$ & $0.0690 \rho$ \\
\hline \multirow{2}{*}{$\begin{array}{l}\text { Perpendicular } \\
\text { to grain }\end{array}$} & 9.5 & 30 & 0.7514 & $0.0865 \rho$ & $0.0712 \rho$ \\
\cline { 2 - 6 } & 12.7 & 45 & 0.7175 & $0.0820 \rho$ & $0.0656 \rho$ \\
\cline { 2 - 6 } & 15.9 & 45 & 0.8040 & $0.0631 \rho$ & $0.0606 \rho$ \\
\hline
\end{tabular}

These regression constants were then plotted against the bolt diameter for each loading direction (Fig: 5.1 and Fig: 5.2) to find the relationship for the embedment strength $\left(f_{h}\right)$, with bolt diameter $(d)$ and the density of timber species $\left(\rho_{k}\right)$. The following relationships were developed.

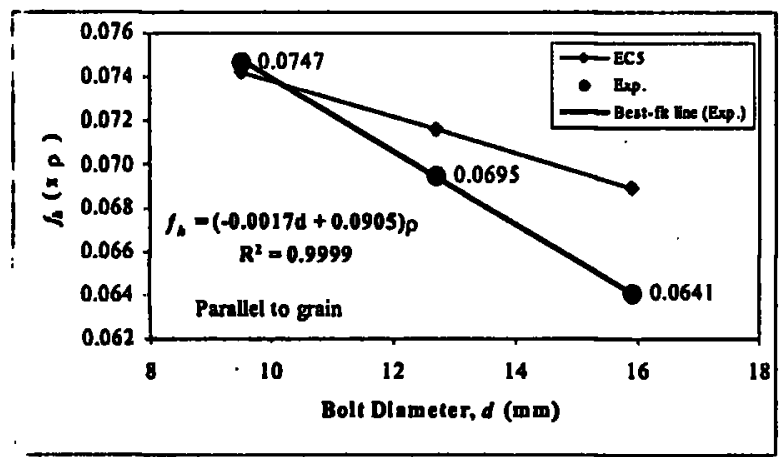

Fig: 5.1: Combined relationship among the embedment strength, density and bolt diameter for parallel to grain loading
From Fig: 5.1, it can be shown that the variation of $f_{h}$ with the specimen density and bolt diameter is given by,

$f_{h}=(-0.0017 d+0.0905) \rho_{k}$

$\therefore f_{h}=0.0905(1-0.019 d) \rho_{k}$

which could be approximated to,

$f_{h}=0.091(1-0.02 d) \rho_{k}$

From Figure 5.2, similarly, for perpendicular to grain loading,

$f_{h}=(-0.0037 d+0.1236) \rho_{k}$ $\therefore f_{h}=0.1236(1-0.039 d) \rho_{k}$

which could be approximated to,

$f_{h}=0.124(1-0.04 d) \rho_{k}$ 


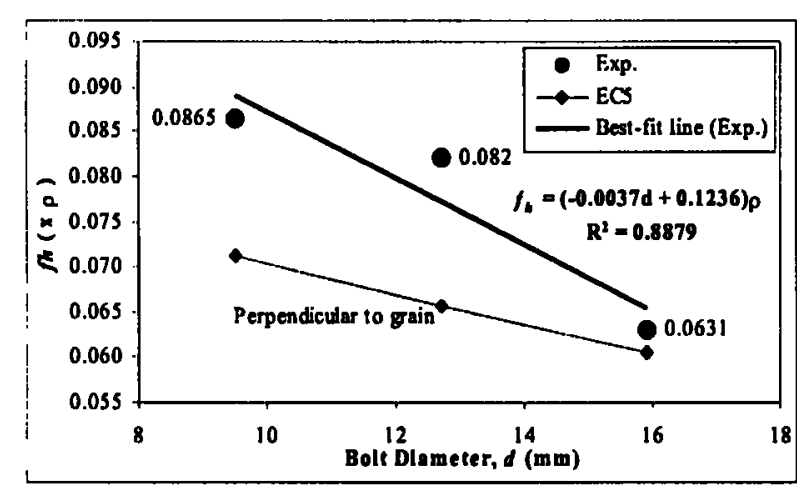

Fig: 5.2: Combined relationship among the embedment strength. density and bolt diameter for perpendicular to grain loading

In annex $\mathrm{A}$ of $\mathrm{EC} 5$, the embedment strength of timber loaded in the direction perpendicular to the grain, is written in the form

$f_{h, \alpha k}=\frac{0.082(1-0.01 d) \rho_{k}}{k_{90}}$

which for hardwoods is

$f_{h, \alpha, k}=\frac{0.082(1-0.01 d) \rho_{k}}{0.90+0.015 d}$

Since we propose an equation of the form for parallel to grain embedment strength

$f_{h}=0.091(1-0.02 d) \rho_{k}$

Rewriting equation (5) in the form of equation 4 , with $k_{90}$ written in the form of $(A+B d)$,

$$
f_{h}=\frac{0.091(1-0.02 d)}{\mathrm{A}+\mathrm{Bd}} \rho_{k}
$$

Coefficients of $A=0.6$ and $B=0.02$ are obtained. $\left(R^{2}=0.6154\right)$ from fig: 5.3 which is the variation of the ratio of coefficients for parallel to grain (using equation. 4) to perpendicular to grain (experimental values) for the three sizes of diameter.
The factor $k_{90}$ is significant for embedment strength of timber at different directions with the grain direction, when it is combined with sine and cosine of the angle to grain. Further work is required to modify $\mathrm{k}_{90}$ according to the embedment strength values at different directions, with the grain direction.

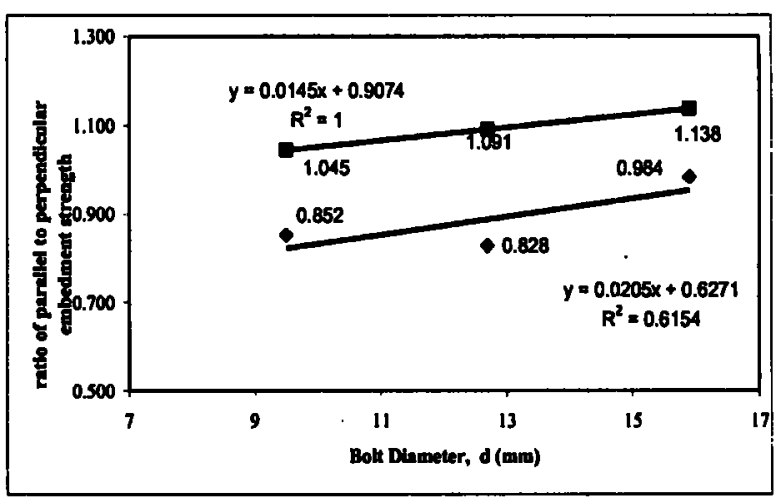

Fig: 5.3 Variation of $k_{o 0}$ - the ratio of coefficients for parallel and perpendicular embedment strengths with bolt diameter

\section{Conclusions and Recommendations}

This paper has demonstrated that the recommendations of EC5 (Equations 1 and 2) should be modified when used for bolted timber joints using timber species indigenous to Sri Lanka. The modified equations for parallel to grain and perpendicular to grain embedment strengths are given by equations 4 , 5 and 6.

Further tests are required to determine the embedment strength for timber loaded at an angle to grain.

\section{References}

1. SMITH, I and FOLIENTE, G. "Load and resistance factor design of timber joints: International practice and future direction" Journal of Structural Engineering. Vol. 128 No: 12002 pp- 48-59.

2. HETTIARACHCHI, M.T.P. "Applications of Eurocode 5 recommendations to bolted 
joints in Sri Lankan timber species". Engineer, Journal of the Institution of Engineers, Sri Lanka Vol. XXXI, No. 1, 2000 pp. 26-39

3. BS EN 383: 1993 "Determination of Embedding Strength and Foundation Values for Dowel-Type Fasteners" British Standard Institution, London.

4. EUROCODE 5 - PART 1.1 "Common Unified Rules for Timber Structures".

5. SMITH, I., WHALE, L.R.J. "Characteristic Properties of Nailed and Bolted Joints Under Short-Term Lateral Load. Part 1: Research Philosophy and Test Programme". Journal of the Institute of Wood Science. Vol.11, No. 3. 1987 pp-5359.

6. WHALE, LR.J. "Mechanical Joints in Tropical Hardwoods - Test Results and Simple Design Equations". Proceedings First Conference of CIB-W18B, Tropical and Hardwood Timber Structures, Singapore. 1987.

7. WHALE, L.R.J, SMITH, I, HILSON, B.O. "Characteristic Properties of Nailed and Bolted Joints Under Short-Term Lateral Load. Part 4: The Influence of Testing Mode and Fastener Diameter Upon Embedment Test Data". Journal of the Institute of Wood Science. Vol.11, No. 5. 1989 pp-156-161.

8. SMITH, I, WHALE, L.R.J, ANDERSON, C., HILSON, B.O. and RODD, P.D. Design properties of laterally loaded nailed or bolted wood joints. Canadian Journal of Civil Engineering. Vol.15, 1988 pp-633643.

9. HILSON, B.O., WHALE, L.R.J., POPE, D.J., SMITH, I. "Characteristic Properties of Nailed and Bolted Joints Under ShortTerm Lateral Load. Part 3: Analysis and Interpretation of embedment test data in terms of density related trends. Journal of the Institute of Wood Science. Issue 62. 1987. pp-65-71.

10. NAWAGAMUWA, A.D. "Application of Eurocode 5 recommendations to bolted joints of Sri Lankan timber species". MPhil. Dissertation. University of Moratuwa, Sri Lanka. 2002

\section{Biographical Sketches}

HETTIARACHCHI, M.T.P. B.Sc. Eng (Hons.) (University of Moratuwa), MSc (London), DIC, PhD (London) is a Senior Lecturer attached to The Department of Civil Engineering, University of Moratuwa. The work described in this paper was carried out under her supervision.

NAWAGAMUWA, A.D. B.Sc. Eng. Hons. (University of Moratuwa), MPhil (University of Moratuwa) MSc (KTH Stockholm) is currently working as a lecturer in the Department of Civil and Environmental Engineering, University of Ruhuna. The contents of this paper are based on the research carried out by him for his Mphil. Degree under the supervision of the main author. 